\title{
Buried bumper syndrome: a rare complication of percutaneous endoscopic gastrostomy
}

\author{
Krzysztof Kurek, Andrzej Baniukiewicz, Agnieszka Świdnicka-Siergiejko \\ Department of Gastroenterology and Internal Medicine, Medical University of Bialystok, Bialystok, Poland
}

Videosurgery Miniinv 2015; 10 (3): 504-507

DOI: 10.5114/wiitm.2015.54056

\begin{abstract}
Feeding via percutaneous endoscopic gastrostomy (PEG) is the preferred form of alimentation when oral feeding is impossible. Although it is a relatively safe method, some complications may occur. One uncommon PEG complication is buried bumper syndrome. In this paper we report a case of buried bumper syndrome, successfully managed with PEG tube repositioning.
\end{abstract}

Key words: buried bumper syndrome, complications, percutaneous endoscopic gastrostomy.

\section{Introduction}

Introduced in 1980 by Gauderer et al. [1] percutaneous endoscopic gastrostomy (PEG) provides a possibility of long-term enteral feeding [1]. Feeding through PEG is indicated in many situations in which normal food administration is impossible, e.g. cancers in the head and neck region and swallowing disturbances. Complications of PEG placement can be divided into two groups. Procedure-related complications are relatively rare and include aspiration during the procedure, acute hemorrhage or even intraperitoneal hematoma and perforation of the small bowel or the colon [2]. Among delayed PEG complications the most common is infection at the PEG site [3]. Other late complications, including tumor implantation, gastrocolocutaneous and aortogastric fistulas, persistent leakage around the PEG site, fungal colonization of the PEG tube and buried bumper syndrome (BBS), have been described [4].

Buried bumper syndrome, first described in 1988 [5], occurs when the internal bumper migrates through the gastric wall [5]. Prevalence of this complication varies in the range $0.3-2.4 \%[6,7]$. Usually
BBS occurs 3-6 months after PEG tube placement [8]. The main cause of BBS is excessive tension between the internal and external bumpers, causing mucosal ischemia and necrosis [4]. Other risk factors include malnutrition, poor wound healing and significant weight gain as a response to effective enteral feeding. Difficulties in infusion of nutrition mixtures through the PEG tube, leakage around the PEG tube and patient's discomfort or even pain during feeding are the main symptoms of BBS and should lead to the proper diagnosis [9]. Various methods have been described to replace the PEG tube in the case of BBS [10-12], and the main purpose is to choose a technique which allows one to avoid PEG tract injury [3,4].

\section{Aim}

The aim of this work was to report a case of BBS successfully treated with endoscopic replacement of the PEG tube.

\section{Case report}

A 52-year-old man with diagnosed inoperative cancer of the root of the tongue underwent PEG (24F, Bos-

\section{Address for correspondence}

Krzysztof Kurek MD, PhD, Department of Gastroenterology and Internal Medicine, Medical University of Bialystok,

24 A M. Sklodowskiej-Curie St, 15-227 Bialystok, Poland, phone: +48 08574682 34, e-mail: krzysztof.kurek@umb.edu.pl 
ton Scientific) placement as a part of palliative management without any immediate complications. Four weeks after the procedure he was admitted because of difficulties in infusion of a nutritious mixture through the PEG tube along with a small amount of peritubal leakage for 2 days. The patient presented moderate pain at the PEG tube site, increasing during palpation. Bowel peristalsis was normal. A bumper-shaped, mobile, painful subcutaneous mass was palpable. The patient's vital signs and laboratory tests were normal. Endoscopic examination of the upper gastrointestinal tract was performed under patient's sedation. The internal bumper was not visible on the gastric wall, and the place of its suspected localization was totally covered by fibrin and gastric mucosa (Photo $1 \mathrm{~A}$ ). The diagnosis of BBS was established. There were no severe ulcerations or necrosis around the buried bumper so we decided to replace it back to the stomach, applying the method described by Ma et al. [11]. Using a needle-knife, radial star-like incisions were made in the gastric mucosa surrounding the migrated PEG. After initial incisions we noticed that the internal bumper was relocated outside the gastric wall (Photo $1 \mathrm{~B}$ ) and further attempts to pull it back to the stomach could be difficult and dangerous. Finally we decided to modify a technique introduced by Venu et al. [9] (Figure 1). The external PEG tube was cut off, leaving about $5 \mathrm{~cm}$ protruding from the skin. Through the shortened and straightened PEG tube the catheter was gently introduced with needle inside under endoscopic control (Photo $2 \mathrm{~A}$ ). Because the orifice in the gastric wall was completely epithelialized and covered with fibrin, the needle was advanced through the gastric mucosa with gentle pulling on the external tube at the same time to avoid PEG tract injury (Photo $2 \mathrm{~A}$ ). The thread was next advanced through the catheter, grasped with a snare and pulled out through the patient's mouth (Figure 1 B). After that, a new PEG (24F, Boston Scientific) tube was fixed to the thread and pulled through the upper gastrointestinal tract. We continued gentle pulling until we felt resistance imposed by the buried bumper on the tip of a new PEG tube (Figure $1 \mathrm{C}$ ). Finally the buried bumper was pulled out from the abdominal wall followed by a new PEG tube. The PEG tube was then placed typically into the correct position without any further complications (Photo 2 B).

\section{Discussion}

Buried bumper syndrome is a delayed PEG placement complication, usually occurring several months after the procedure. However, there are described cases of BBS as soon as 10 days after PEG placement [13]. In that situation the PEG tube can be salvaged and repositioned to the stomach without the need of replacement [14]. Although in our case BBS was recognized early, the orifice in the gastric wall was covered by fibrin and gastric mucosa; moreover, the internal bumper had migrated outside the gastric wall, so pulling the PEG tube back to the stomach using forceps or snare was impossible.

Even though BBS occurs relatively rarely, in up to $2.4 \%$ of PEG placements, it can lead to patient's death due to peritonitis [15]. To prevent this serious complication, it is important to leave an approxi-
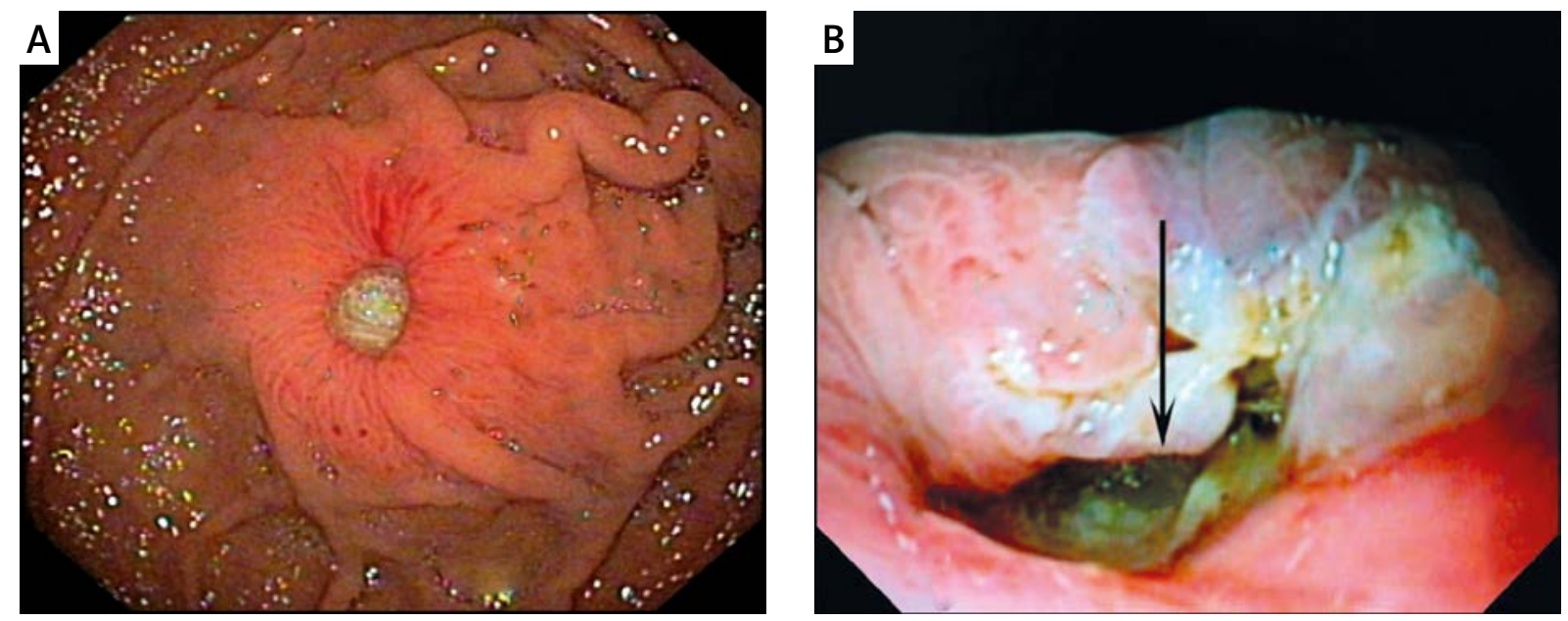

Photo 1. Endoscopic view of buried bumper syndrome (A). Complete migration of internal bumper outside gastric wall (arrow) (B) 

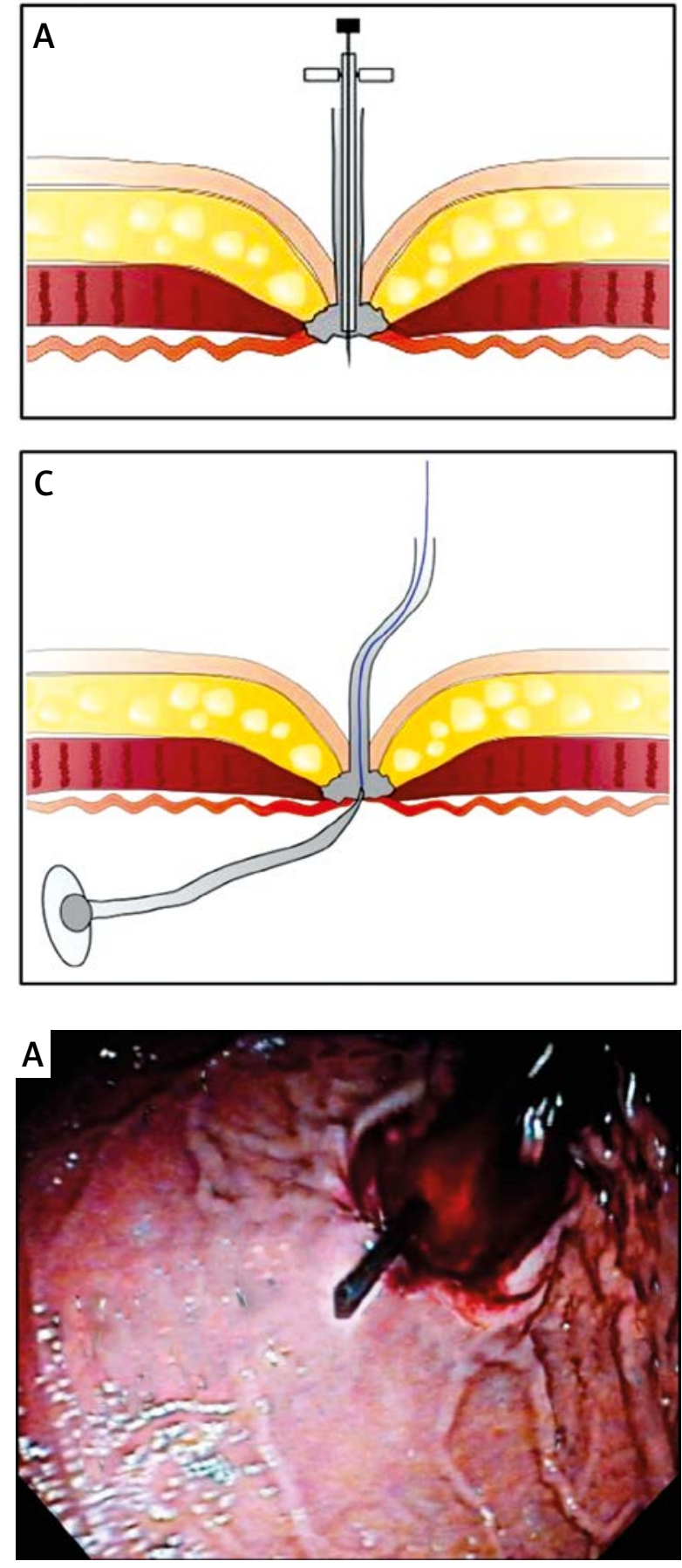

Photo 2. Endoscopic view of advancing catheter with needle inside to the stomach (A). Endoscopic view of correctly placed new internal bumper (B)

mately 3-5 $\mathrm{mm}$ free space between skin level and the external bumper. Such management prevents excessive tension of the internal bumper to the gastric wall, mucosal ischemia and ulceration [16]. Some authors also recommend gently rotating the PEG tube daily [17]. This practice guarantees that

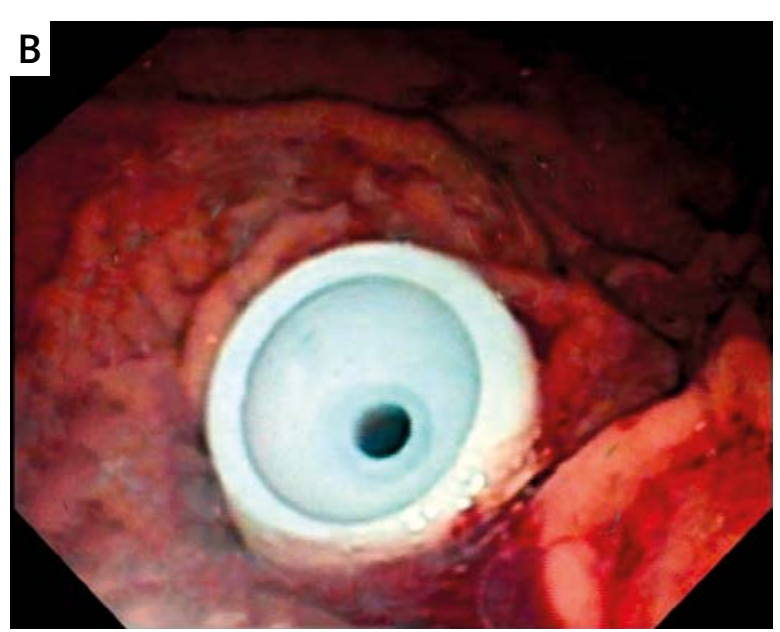

Figure 1. Introduction of catheter with the needle inside through the cut off straightened PEG tube (A). Advancing the thread through the catheter and grasping it with the snare (B). Pulling the new PEG tube (C)

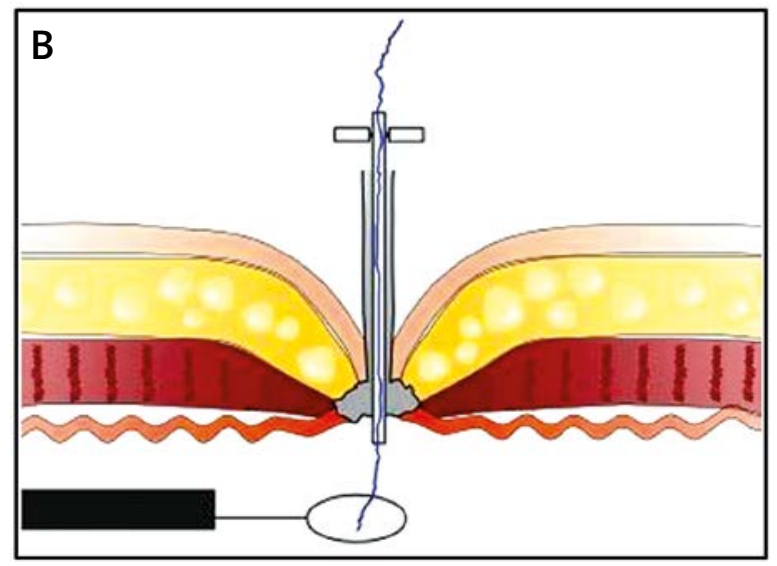

the internal bumper will not be buried within the gastric wall [10].

In cases of PEG migration during the first 4 weeks after placement the risk of peritonitis is the highest because of leak of gastric contents into the peritoneum through the immature PEG track [18]. 
In the case of our patient we did not observe any signs of developing peritonitis. However, we noticed malfunction of the PEG tube and peritubal leakage, also described by other authors, which allowed us to establish the proper diagnosis and perform prompt management. Failure to recognize BBS may lead to migration of the internal bumper outside through the abdominal wall [10].

Percutaneous endoscopic gastrostomy tube replacement in case of BBS is technically demanding and can be a challenge for the endoscopist. Various techniques and methods have been described to remove PEG tubes in such situations. Unfortunately none of them ensures success in all cases. Bumpers buried completely in a gastric wall and covered with fibrin and mucosa may become apparent by needle-knife radial incision and then removed with forceps [11]. In the case of our patient, the method reported by Ma et al. [11] failed because of complete migration of the bumper outside the gastric wall. The widely accepted option of BBS treatment is removal of the buried bumper and replacement with a new PEG tube at the same time. Another method introduced by Fay et al. [19] and a similar method described by Venu et al. [9] are relatively simple to perform, require no additional equipment and provide a new PEG placement simultaneously with removal of the migrated internal bumper. In the case of our patient we improved the method described by Venu et al. [9] without any difficulties or further complications.

\section{Conclusions}

Feeding via percutaneous endoscopic gastrostomy is the preferred form of alimentation when oral feeding is impossible. A rare complication of PEG is the buried bumper syndrome, which occurs when the internal bumper migrates through the gastric wall. Various techniques have been described to remove PEG tubes in the situation of buried bumper syndrome. In the case of our patient we modified and improved previously described methods, with promising results.

\section{Acknowledgments}

This study was support by Medical University of Bialystok, grant no: N/ST/ZB/15/011/1118.

\section{Conflict of interest}

The authors declare no conflict of interest.

\section{References}

1. Gauderer MW, Ponsky JL, Izant RJ Jr. Gastrostomy without laparotomy: a percutaneous endoscopic technique. J Pediatr Surg 1980; 15: 872-5.

2. McClave SA, Chang WK. Complications of enteral access. Gastrointest Endosc 2003; 58: 739-51.

3. Gossner L, Keymling J, Hahn EG, Ell C. Antibiotic prophylaxis in percutaneous endoscopic gastrostomy (PEG): a prospective randomized clinical trial. Endoscopy 1999; 31: 119-24.

4. Lynch CR, Fang JC. Prevention and management of complications of percutaneous endoscopic gastrostomy (PEG) tubes. Pract Gastroenterol 2004; 28: 66-76.

5. Levant JA, Drennen F, McDonald GB. Retraction of the SacksVine gastrostomy tubes into the gastric wall: report of seven cases [Abstract]. Gastrointest Endosc 1988; 34: 215.

6. Giuliani S, Pane A, Dall'Oglio L, et al. Clinical manifestations and management of buried bumper syndrome in patients with percutaneous endoscopic gastrostomy. Gastrointest Endosc 2009; 69: 1193.

7. Baskin WN. Acute complications associated with bedside placement of feeding tubes. Nutr Clin Pract 2006; 21: 40-55.

8. Khalil Q, Kibria R, Akram S. Acute buried bumper syndrome. South Med J 2010; 103: 1256-8.

9. Venu RP, Brown RD, Pastika BJ, et al. The buried bumper syndrome: a simple management approach in two patients. Gastrointest Endosc 2002; 56: 582-4.

10. Boyd JW, DeLegge MH, Shamburek RD, Kirby DF. The buried bumper syndrome: a new technique for safe, endoscopic PEG removal. Gastrointest Endosc 1995; 41: 508-11.

11. Ma MM, Semlacher EA, Fedorak RN, et al. The buried gastrostomy bumper syndrome: prevention and endoscopic approaches to removal. Gastrointest Endosc 1995; 41: 505-8.

12. Turner P, Deakin M. Percutaneous endoscopic gastrostomy tube removal and replacement after "buried bumper syndrome": the simple way. Surg Endosc 2009; 23: 1914-7.

13. Kejariwal D, Aravinthan A, Bromley D, Miao Y. Buried bumper syndrome: cut and leave it alone! Nutr Clin Pract 2008; 23: 322-4.

14. Bhat G, Suvarna D, Pai Cg. Acute buried bumper syndrome: an endoscopic peg tube salvage approach. Indian J Med Sci 2010; 64: 234-6.

15. Anagnostopoulos GK, Kostopoulos P, Arvanitidis DM. Buried bumper syndrome with a fatal outcome, presenting early as gastrointestinal bleeding after percutaneous endoscopic gastrostomy placement. J Postgrad Med 2003; 49: 325-7.

16. Gençosmanoğlu R, Koç D, Tözün N. The buried bumper syndrome: migration of internal bumper of percutaneous endoscopic gastrostomy tube into the abdominal wall. J Gastroenterol 2003; 38: 1077-80.

17. Löser C, Aschl G, Hébuterne X, et al. ESPEN guidelines on artificial enteral nutrition: percutaneous endoscopic gastrostomy (PEG). Clin Nutr 2005; 24: 848-61.

18. Mellinger JD, Simon IB, Schlechter B, et al. Tract formation followig percutaneous endoscopic gastrostomy in an animal model. Surg Endosc 1991; 5: 189-91.

19. Fay DE, Luther R, Gruber M. A single procedure endoscopic technique for replacing partially extruded percutaneous endoscopic gastrotomy tubes. Gastrointest Endosc 1990; 36: 298-300.

Received: 23.04.2015, accepted: 21.07.2015. 